\title{
BMJ Open Assessment of equity in healthcare financing and benefits distribution in Tanzania: a cross-sectional study protocol
}

\author{
Peter Binyaruka (D) , August Kuwawenaruwa, ${ }^{1}$ Mariam Ally, ${ }^{2}$ Moritz Piatti, ${ }^{2}$ \\ Gemini Mtei ${ }^{3}$
}

To cite: Binyaruka $P$, Kuwawenaruwa A, Ally M, et al. Assessment of equity in healthcare financing and benefits distribution in Tanzania: a cross-sectional study protocol. BMJ Open 2021;11:e045807. doi:10.1136/ bmjopen-2020-045807

- Prepublication history and additional supplemental material for this paper are available online. To view these files, please visit the journal online. (http://dx.doi.org/10.1136/ bmjopen-2020-045807).

Received 23 0ctober 2020 Accepted 16 August 2021

\section{Check for updates}

\section{(c) Author(s) (or their} employer(s)) 2021. Re-use permitted under CC BY-NC. No commercial re-use. See rights and permissions. Published by BMJ.

${ }^{1}$ Department of Health System, Impact Evaluation and Policy, Ifakara Health Institute, Dar es Salaam, Dar es Salaam, Tanzania, United Republic of

${ }^{2}$ The World Bank, Dar es Salaam, Tanzania, United Republic of

${ }^{3}$ Abt. Associates Inc, USAID Public Sector Systems Strengthening Plus (PS3+) Project, Dar es Salaam, Tanzania, United Republic of

Correspondence to Dr Peter Binyaruka; pbinyaruka@ihi.or.tz

\section{ABSTRACT}

Introduction Achieving universal health coverage goal by ensuring access to quality health service without financial hardship is a policy target in many countries. Thus, routine assessments of financial risk protection, and equity in financing and service delivery are required in order to track country progress towards realising this universal coverage target. This study aims to undertake a systemwide assessment of equity in health financing and benefits distribution as well as catastrophic and impoverishing health spending by using the recent national survey data in Tanzania. We aim for updated analyses and compare with previous assessments for trend analyses.

Methods and analysis We will use cross-sectional data from the national Household Budget Survey 2017/2018 covering 9463 households and 45935 individuals cross all 26 regions of mainland Tanzania. These data include information on service utilisation, healthcare payments and consumption expenditure. To assess the distribution of healthcare benefits (and in relation to healthcare need) across population subgroups, we will employ a benefit incidence analysis across public and private health providers. The distributions of healthcare benefits across population subgroups will be summarised by concentration indices. The distribution of healthcare financing burdens in relation to household ability-to-pay across population subgroups will be assessed through a financing incidence analysis. Financing incidence analysis will focus on domestic sources (tax revenues, insurance contributions and out-of-pocket payments). Kakwani indices will be used to summarise the distributions of financing burdens according to households' ability to pay. We will further estimate two measures of financial risk protection (ie, catastrophic health expenditure and impoverishing effect of healthcare payments).

Ethics and dissemination We will involve secondary data analysis that does not require ethical approval. The results of this study will be disseminated through stakeholder meetings, peer-reviewed journal articles, policy briefs, local and international conferences and through social media platforms.

\section{INTRODUCTION}

Many countries are committed to achieve universal health coverage (UHC) as a
Strengths and limitations of this study

- This study will use more recent national household data that include information on healthcare utilisation.

- The study will reflect the progress of ongoing health sector reforms to enhance equity towards universal health coverage.

- Qualitative research to explain the observed equity patterns in financing and benefit distribution is lacking.

- The contributions to healthcare through taxes and health insurance will be estimated from household consumption expenditure.

primary goal (goal 3.8) of the Sustainable Development Goal 3 for health. ${ }^{1}$ The UHC goal ensures that everyone has access to good quality healthcare without incurring financial hardship due to healthcare payment. ${ }^{2}$ Health systems in low-income and middleincome countries (LMICs) are often financed through donor support, tax revenue, health insurance contributions and out-of-pocket payments. $^{2-4}$ Prepayment financing mechanisms that can be channelled to finance healthcare like general taxation (via a health budget) and health insurance can ensure financial protection as opposed to direct outof-pocket payments. ${ }^{5}$ Yet, these prepayment mechanisms (taxes and insurance) are inadequately or inefficiently implemented in many LMICs, partly because of limited fiscal space (inadequate government revenue) ${ }^{6}$ or limited ability to pay and practical challenge to cover the population that works in informal sector. ${ }^{7}$ Out-of-pocket payment remains a predominant mechanism of financing healthcare in poor countries, such that a high proportion of households are being pushed into poverty due to catastrophic healthcare expenditure. ${ }^{289}$ Poor and disadvantaged households 
in LMICs are also inadequately accessing or benefiting from healthcare. ${ }^{4}$ Thus, the health financing burden and access to healthcare benefits in LMICs reflects inequitable health systems, which may slow the progress towards UHC. Hence, there is a need to routinely monitor and assess progress towards the UHC goal, especially on equity in financing and healthcare delivery across LMICs.

Equity is an intermediate goal of UHC, and this principle requires that households should contribute to the health system according to their ability to pay and should receive health benefits according to their healthcare needs. ${ }^{3} 10$ Equity assessments have been largely done in high-income countries, ${ }^{11-13}$ with limited studies in LMICs due to data limitations in most cases. ${ }^{14}$ To date, however, there is an increase in studies assessing equity in health financing and benefits distribution in $\mathrm{LMICs}^{4}$ and often using benefit and financing incidence analyses. ${ }^{15} 16$ Financing incidence analysis focuses on assessing the distribution of the healthcare financing burden across socioeconomic groups and in relation to their ability to pay, ${ }^{15} 1718$ while benefit incidence analysis focuses on assessing the distribution of healthcare benefits across population socioeconomic groups and according to healthcare need. ${ }^{16} 18$ Recently, a systematic review of studies on benefit and financing incidences analysis in LMICs were conducted and concluded broadly that healthcare benefits are predominantly received by rich than poor populations, and the overall burden of financing also falls more on the rich. ${ }^{4}$ Furthermore, the financial risk protection for UHC is increasingly been assessed in LMICs, ${ }^{19-29}$ mainly through incidences of catastrophic health expenditure and impoverishing effects of direct health payments.

In Tanzania, the assessments of equity in healthcare financing, benefits distribution and catastrophic health spending have been conducted previously. ${ }^{30-32}$ Mtei $e t a l^{31}$ found that the Tanzanian healthcare financing system was marginally progressive overall because all income taxes and National Health Insurance Fund contributions were most progressive sources, while out-of-pocket payments and Community Health Fund contributions were regressive. The healthcare benefits were found to be fairly distributed across socioeconomic status, although the poorest received a lower share of benefits relative to their share of healthcare needs. ${ }^{31}$ The benefit incidence analysis by Mtei et al, ${ }^{31}$ however, relied on a sample of 2224 households from seven districts, which did not include a representative sample of all Tanzanians. In terms of financial protection, they found about $2 \%$ and $1 \%$ of Tanzanians faced financial catastrophe and were impoverished due to out-of-pocket payments, respectively. ${ }^{30} 32$

Since the previous assessments of catastrophic payments and equity in financing and benefit distribution in Tanzania are outdated as they used data of 2001 and $2007,{ }^{30-32}$ and there is a number of ongoing health sector reforms (ie, reforms on financing and service provision) in the country over the last decades, there is a need to reassess the health system equity and take a step further to compare our estimates with previous assessments for trend analysis from 2001 to 2018, as a way to monitor progress towards the UHC in Tanzania. This study will also produce baseline estimates for assessing the more recent reforms for future evaluation. Therefore, this study proposes to conduct a system-wide assessment (involving multiple health providers and financing sources) by using the most recent national Household Budget Survey dataset of 2017/2018, which includes both health financing and service utilisation information. Specifically, this study aims to: (1) assess the equity in healthcare financing system from multiple financing sources, (2) assess the equity in the distribution of healthcare benefits from multiple providers and (3) measure the status of catastrophic and impoverishing healthcare payments.

\section{Tanzanian health system context}

Tanzania is a lower middle-income country in East Africa with an estimated population of around 56 million people in $2016 .{ }^{33}$ Tanzania has 31 regions (26 for mainland Tanzania) and most (70\%) inhabitants are residing rural areas.

\section{Health financing system}

Tanzanian health financing system is highly fragmented with various sources of financing. Healthcare is largely financed internally through domestic sources, that is, $64 \%$, while $36 \%$ is through external sources. ${ }^{3435}$ According to the National Health Accounts for 2015/2016, the relative share to the total health expenditure by financing sources is as follows: general taxation (34\%), health insurance schemes $(8 \%)$, out-of-pocket payments $(22 \%)$ and donor support (36\%). In Tanzania, about $6 \%$ of the Gross Domestic Product (GDP) is invested in healthcare, and $12 \%$ of government expenditure or total budget is spent on health, but still below the Abuja Declaration target of 15\%. ${ }^{346}$ The recent health sector review in 2018 revealed that $33 \%$ of Tanzanians were covered by health insurance: $7 \%$ by National Health Insurance Fund for public formal sector employees mainly and mandatory, $25 \%$ by Community Health Fund as a voluntary scheme for informal sector workers and $1 \%$ covered by private health insurance schemes and other schemes. ${ }^{37}$ Tanzania also has exemption and waiver policy to protect the poor and vulnerable groups (pregnant women, children under 5 years and elderly above 60 years) from financial risks of paying out of pocket for healthcare. However, the enforcement of these policies is weak. ${ }^{38} 39$

In terms of healthcare financing reforms, Tanzania is implementing reforms in health insurance schemes to improve access and financial protection. These includes:

1. The introduction of improved Community Health Fund from 2017/2018 that aimed to extend the coverage to the population working in the informal sector, as an intermediate strategy towards a single national health insurance. ${ }^{40}$

2. The shift of Community Health Fund management from the Ministry of Health to National Health Insur- 
ance Fund in 2009 in order to harmonise management operations and improve administrative efficiency. ${ }^{41}$

3. Extending target beneficiaries for the National Health Insurance Fund from 2012. The scheme is mandatory for public sector workers, but since 2012, they allowed individuals from the private sector and informal sectors to enrol in order to extend the coverage.

4. National Health Insurance Fund has also introduced various special benefit packages since 2018/2019 for children, students and retired employees.

The previously mentioned financing reforms are expected to improve the equity in health financing by granting fair distribution of financing burden. We therefore hypothesise that the proposed analyses will reveal a more equitable health financing system such that people are contributing to healthcare based on their ability to pay, with reduced incidences of catastrophic and impoverishing health spending.

\section{Healthcare delivery system}

The health services in Tanzania are delivered by public providers, private for-profit providers and private notfor-profit providers (faith-based organisation facilities). The public sector is the largest sector of the Tanzanian health system with more than $70 \%$ of facilities, but private for-profit and the faith-based organisation facilities serve as important complements. ${ }^{42}$ The public health system has a hierarchical administrative structure and is organised in a referral structure with dispensaries and health centres providing primary healthcare services, followed by district, regional and referral hospitals. A recent review of the health sector in Tanzania showed an increase in service coverage including family planning, antenatal care, delivery care, postnatal care, HIV treatment and counselling. ${ }^{37}$

A number of health sector reforms are implemented in Tanzania to improve healthcare service delivery, quality and access. These include for example:

1. The implementation of Primary Health Service Development Programme (2007-2017) to improve access to basic healthcare service. This programme focused on rehabilitation and construction of at least one dispensary per village and a health centre per each ward countrywide. ${ }^{43}$

2. Implementing public private partnership policy to increase the availability of quality healthcare services. Public-private partnership policy include service agreements with private not-for-profit healthcare providers from 2008 . $^{43}$

3. Implementation of the Direct Health Facility Financing mechanism from 2017/2018 countrywide to improve efficiency in service delivery and resource use. It involves direct transfer of the Health Basket Fund (donor funds earmarked for the health sector) from the Ministry of Finance to all health facilities' bank accounts, which could improve efficiency, autonomy and effectiveness of resources use for service delivery. ${ }^{44}$
4. Improvement in provider payment mechanisms for improved Community Health Fund and Direct Health Facility Financing through formula-based capitation from 2017/2018 in order to improve providers' responses to quality of care, efficiency in resource use and allocation and improve access to the poor. These formula accounts for population needs, equity and facility performance on utilisation indicators as key adjustors.

5. Results-based financing programme in nine regions (2015-2020) in order to improve health service delivery and utilisation. It involves paying health providers based on their performance in service quality and coverage indicators that may stimulate providers to improve healthcare quality, delivery and utilisation. ${ }^{45}$

6 . Government initiative to increase the budget for procurement of drugs and supplies (2015-2020) in order to increase drug availability, as a proxy of facility quality, and attract more patients especially in rural and remote areas. This also could reduce the out-of-pocket payments through reduced costs of buying drugs in private pharmacies.

All these reforms are anticipated to improve the benefit distribution across population subgroups by granting equal access to care based on healthcare needs. We therefore hypothesise that the proposed analyses will reveal a more equitable distribution of health benefits such that people are benefiting from healthcare based on their healthcare need.

\section{Methods and materials}

\section{Study design}

The assessment of equity in financing and benefits distribution will rely on quantitative methods by analysing secondary data from the cross-sectional household budget survey of 2017/2018 in Tanzania. We are aiming for updated analyses and compare with previous assessments for trend analyses.

\section{Data sources}

We will use the national representative data from the household budget survey for year 2017/2018, which includes utilisation data for undertaking a benefit incidence analysis; the utilisation data were lacking in previous household budget surveys in Tanzania. ${ }^{31}$ The 2017/2018 household budget survey was implemented by the National Bureau of Statistics ${ }^{46}$ and adopted a twostage cluster sample design. The first stage involved selection of enumeration areas as primary sampling units from 2012 national census frame. The second stage involved systematic sampling of households from the primary sampling units list (12 households per unit). The survey covered a sample of 9463 households and 45935 individuals from 26 regions of the mainland Tanzania. Data were collected from December 2017 to November 2018, and they used both survey questionnaires and diaries to capture information. The household budget survey data 
include information on socioeconomic and demographic characteristics, households' consumption and expenditure, illness and injury status, healthcare utilisation and payments, and other non-health information (see online supplemental appendix table 1). While household budget survey data are the main data source in this proposed study, additional data on tax rates and structure will be obtained from the Tanzania Revenue Authority in order to supplement the financing incidence analysis for tax revenues. Data for unit costs will be obtained from National Health Insurance Fund based on claims reimbursement and service use for the financial year 2017/2018 but will be supplemented (for sensitivity analysis) by unit costs estimated from a costing study commissioned by the ministry of health in Tanzania. ${ }^{47}$ The costing data will be inflated to 2018 prices.

\section{Measurement of household living standard}

The measures of living standard are useful in assessing the distribution of any outcome of interest including health variables. In this study, household consumption expenditure and wealth index will be used as two measures of living standard as opposed to household income. ${ }^{151618}$ The consumption expenditure will be our primary measure of living standard, while the wealth index will be used for sensitivity analysis. The wealth index will be constructed by using information on household ownership of different assets and household features through a principal component analysis. ${ }^{48}$ The consumption expenditure (and wealth index) will be used to rank and categorise households into quintiles of equal size, with quintile 1 including the poorest $20 \%$ of the population, while quintile 5 including the richest $20 \%$.

The consumption expenditure data will be adjusted for household size and demographic composition to obtain an adult equivalent estimate, reflecting individual welfare as opposed to household welfare. ${ }^{49}$ The estimation of adult equivalent scale will use the following formula:

$$
\text { Adult Equivalent }=(A+\alpha K)^{\theta},
$$

where $A$ is the number of adults in the household (15 years and above), $K$ is the number of children (less than 15 years), $\alpha$ is the cost of children and $\theta$ is the degree of economies of scale. If $\alpha$ equals 1 , then the consumption of a child is equivalent to that of an adult, and when $\theta$ equals 1 , then there is absence of economies of scale such that larger households, on average, do not live more cheaply than smaller households. ${ }^{15}$ Deaton and Zaidi $^{49}$ suggest that, for developing countries, the value of $\theta$ should be between 0.75 and 1.0, while the value of $\alpha$ should lie between 0.3 and 0.5 . This is because of the relative importance of food in total consumption and the limited scope for economies of scale. In this case, we will assume the values of $\alpha$ and $\theta$ to be 0.5 and 0.75 , respectively, as previously considered in Tanzania ${ }^{31}$ and elsewhere. $^{50}$

\section{Data analysis}

Our proposed analyses will be categorised into three parts in accordance with study objectives. This will include the assessment of progressivity in health financing through financing incidence analysis, assessment of healthcare benefit distribution through benefit incidence analysis and the assessment of catastrophic and impoverishing healthcare payments.

\section{Financing incidence analysis}

We will first assess the progressivity of each health financing source, and then overall progressivity of the entire health financing system. Financing incidence analysis focuses on the distribution of shares/incidence of payments to finance health out of total household resource compared with the distribution of household living standard (ie, ability to pay). In this proposed study, financing incidence analysis will be conducted on three main domestic health financing mechanisms, that is, revenue from taxes, health insurance contributions and out-of-pocket payments. Although donor support is among the financing sources, we will exclude that external source as we aim primarily to evaluate the distributional impact of domestic financing burdens. Note that including external source would reflect that financing burden is falling on citizens of the donor country as primary financiers of donor funds. The focus of this paper is assessing how financing burden is distributed among local citizens in financing their healthcare.

Incidence of out-of-pocket payments: this will be estimated from the household budget survey data, where direct expenditure on healthcare were recorded for the past 3 months and 1 year prior to the survey. Direct healthcare spending includes user fees or out-of-pocket payments for medicines, consultations, medical laboratory, treatments and procedures. These healthcare payments excluded transport costs and insurance contributions. We will therefore aggregate to obtain a total direct healthcare expenditure per household and estimate shares of outof-pocket payments per household from total household consumption expenditure.

Incidence of health insurance contributions: we will consider only two main types of health insurance in Tanzania: National Health Insurance Fund and Community Health Fund. Other insurance schemes will be excluded because of limited coverage $(<2 \%)^{37}$ and also due to limited information on respective premiums especially for private health insurance. The estimation of shares of insurance contributions from total household consumption expenditure will use the known share of payroll deduction for National Health Insurance Fund and known premiums of Community Health Fund. In particular, formal public sector workers are meant to contribute $3 \%$ of their income to the National Health Insurance Fund (and complemented by $3 \%$ from their employers), while Community Health Fund members are paying an annual premium of Tanzanian shillings (TZS) 30 000/- per household of six 
and TZS 150 000/- only per household of six located in Dar es Salaam region. ${ }^{40}$

Incidence of tax contributions: we will estimate tax contributions for both direct and indirect taxes. Direct taxes will include mainly personal income tax, while indirect tax will include value added taxes, excise taxes and import duty. A number of assumptions will be considered in estimating various tax contributions, because all contribution shares will be estimated from total household expenditure. For example, the personal income tax will be limited to formal sector workers by applying respective tax rate/ structure based on income group from Tanzania Revenue Authority. Value added taxes will be applied on respective commodities purchased based on national tax rate of 18\% from Tanzania Revenue Authority (only excluding exempted items). Since it is difficult to distinguish between imported and domestically produced commodities for import duty, we will impose some assumptions for the likelihood of good being imported.

\section{Analytical methods}

To assess the distribution of financing burden for each source of financing, we will use both structural and effective progressivity approach. ${ }^{15}$ Structural progressivity approach involves estimating the share of healthcare financing contributions from consumption expenditure for each subgroup (quintile) of household living standard (ie, household consumption expenditure). Note that household consumption expenditure is a measure of household ability to pay. This approach assesses how healthcare payments as a share of total household resources vary across subgroups / quintiles of households. In this approach, a health financing system is considered progressive (regressive) if the richer subgroup contributes to healthcare a relatively higher (lower) proportion of their resources than poorer subgroups. ${ }^{18}$ Also, a financing mechanism is considered proportional if the shares of payments remain constant across quintiles.

Since structural approach does not account for distribution of ability to pay, we will further apply effective progressivity approach. ${ }^{15}$ This involves the use of concentration index and Kakwani index. ${ }^{1851}$ These indices are computed from the concentration curve and the Lorenz curve, respectively. Lorenz curve plots cumulative share of income earned/household resources (ability to pay) (y-axis) against ranked population by income (x-axis). A Lorenz curve below the diagonal line shows an income inequality in favour of the rich and vice versa. Lorenz curve is summarised by a Gini index, which is calculated as the ratio of the area that lies between the line of equality and the Lorenz curve over the total area under the line of equality. The concentration curve plots the cumulative share of an outcome of interest like healthcare payments (y-axis) against the cumulative share of the households ranked by ability to pay (x-axis). Concentration curves have a $45^{\circ}$ line/diagonal line, as a line of equality, and a concentration curve below (above) the line of equality shows pro-rich (pro-poor) distribution. A concentration curve is summarised by a concentration index, which is calculated as twice the area between the $45^{\circ}$ line and the concentration curve. It is conventionally calculated using covariance between an outcome of interest and the fractional rank in the living standards (expenditure) distribution, as shown in the equation below. ${ }^{18} 51$

$$
\text { Concentration Index }=\frac{2}{\mu} \operatorname{cov}\left(y_{i}, R_{i}\right),
$$

where $y_{i}$ is the outcome of interest (eg, healthcare financing variable) of the $i^{t h}$ household; $R_{i}$ is the fractional rank of the $i^{\text {th }}$ household (in terms of household living standard, with lower fractions for poorest and larger fractions for richest); $\mu$ is the mean of the outcome of interest (eg, payment variable); and cov denotes the covariance. The concentration index ranges between $(-1$ and +1$)$, whereby zero indicates equality across socioeconomic status subgroups, while negative and positive values indicate that burden of healthcare payments is more among the poor and rich, respectively. ${ }^{18}$

Thus, a Kakwani index of progressivity of health financing mechanism $j$ is computed as follows ${ }^{51}$ :

$$
\pi_{j}=C_{j}-G_{x},
$$

where $C_{j}$ is the concentration index of health financing mechanism $j$, and $G_{x}$ is the Gini index of the consumption expenditure (measure of ability to pay). The Kakwani index ranges from -2 (ie, most regressive) to 1 (most progressive). In other words, a financing source is progressive (or regressive) when $\pi_{j}>0\left(\right.$ or $\left._{\pi_{j}}<0\right)$, while a financing mechanism is proportional when $\pi_{j}=0$. A dominance test to compare multiple concentration curves and Lorenz curve will be performed to assess whether the concentration curve of healthcare payments is statistically different from the Lorenz curve of income distribution or the line of equality. ${ }^{18}$

\section{Benefit incidence analysis}

We will conduct a benefit incidence analysis for systemwide assessment including public and private providers as well as for public subsidy only (total benefits net of individual user fees payments). ${ }^{1618}$ Healthcare benefits will be computed by multiplying the utilisation rates/healthcare use and unit costs of the specific service. The unit cost data will be extracted from National Health Insurance Fund claims reimbursement, but also unit costs from the available costing study in Tanzania ${ }^{47}$ for sensitivity analysis. Data on both inpatient and outpatient utilisation will be obtained from the household budget survey data, which include utilisation rates in 2 weeks before the survey and by provider types. The number of outpatient visits and inpatient stays will be annualised by multiplying the reported outpatient visits and inpatient stays in the last 2 weeks by 26 to obtain annual household visits. ${ }^{52} 53$

We will also assess the distribution of healthcare benefits according to peoples' healthcare needs. ${ }^{16}$ Healthcare needs are often based on the individual reported self-assessed health, illness and possible symptoms. Since self-assessed health was not captured in the household 
budget survey data, we will use the indicator variable of peoples' illness in the last 2 weeks prior to the survey as a proxy for healthcare need. As previously categorised in other studies, ${ }^{505254}$ we will generate two groups of people based on their healthcare needs, as good and bad health status. We will also use peoples' disability status as a proxy measure of healthcare need for a sensitivity analysis. ${ }^{55}$

\section{Analytical methods}

To assess the healthcare benefit distribution, we will construct bar charts showing the relative share of total benefits received by each quintile of household consumption expenditure. We will further compute concentration index to measure the degree of pro-poorness (prorich) distribution of benefit and present corresponding concentration curves of cumulative shares of benefits against cumulative share of ranked households by expenditure quintiles. ${ }^{18}$ We will also perform a dominance test between curves and compare the distribution of healthcare benefits against the distribution of need to ascertain the fairness in healthcare benefits.

\section{Assessing catastrophic and impoverishing healthcare payments}

We will further assess financial catastrophe and impoverishing effect of out-of-pocket payments as two preferred measures of financial protection in a health system. ${ }^{56}$

Catastrophic healthcare expenditure: we will estimate the incidence and intensity of catastrophic health spending. Healthcare spending is termed catastrophic if it exceeds a prespecified threshold of households' resources (ie, consumption expenditure). We will use $10 \%$ threshold of total expenditure and $40 \%$ threshold of non-food expenditure ${ }^{818}$ However, additional thresholds ranging between $5 \%$ and $40 \%$ will be considered for robustness check. The incidence of catastrophic spending will be computed as a proportion of households, expressed by headcount, that incurred catastrophic payments for healthcare. We will also compute the catastrophic payment overshoot and mean positive overshoot. The catastrophic payment overshoot is the average degree to which catastrophic spending exceeded a certain threshold (intensity of catastrophic spending in the whole sample), while the mean positive overshoot is the ratio of overall overshoot and headcount to reflect the severity of catastrophic spending. ${ }^{18}$ Since the measures of headcount and overshoot does not account for whether the threshold was exceeded by poor or rich households, we will further compute weighted headcount and weighted overshoot to account for differences in the distribution of catastrophic payments by multiplying the headcount and overshoot by one minus concentration index of headcount and overshoot.

Impoverishing healthcare payments: we will further assess the impact of out-of-pocket payments for healthcare on poverty. This is estimated as a difference between a poverty level with the gross of out-of-pocket payments (before healthcare payments) and a poverty level with the net of out-of-pocket payments (after healthcare payments). ${ }^{56}$
We will therefore present four conventional measures of impoverishments ${ }^{18}$ : (1) poverty headcount: showing the proportion of households living below the prespecified poverty line; (2) poverty gap: showing the aggregate discrepancy in household resources from the poverty line; (3) normalised poverty gap: showing the percent of poverty gap from the poverty line (ie, obtained by dividing the poverty gap by the specific poverty line); and (4) normalised mean poverty gap: showing the severity of impoverishing among the poor. Normalised poverty gap is useful for international comparisons where countries use different poverty lines and currency units. ${ }^{18}$ We intend to use three poverty lines in this assessment: two at the national level and one at the international level. This will include the Tanzanian basic needs (overall) poverty line (TZS 49320 per adult equivalent per month); food poverty line (TZS 33748 per adult equivalent per month); and the World Bank poverty line (US\$ 1.25 per day per person in 2005 purchasing power parity terms). We will also draw a Pen's parade chart to illustrate graphically the impoverishing effects of out-of-pocket payments. The Pen's parade chart plot household expenditure gross and net of out-of-pocket payments on the y-axis against the cumulative proportion of individuals ranked by expenditure on the x-axis from poorest to richest. ${ }^{18}$ All analyses will account for sampling weights from the household budget survey dataset and will be performed in STATA V.16.

\section{Patient and public involvement}

No patient involved.

\section{DISCUSSION}

This study will show the more recent status of equity in healthcare financing and benefits distribution as well as assess the status of catastrophic and impoverishing health payments in Tanzania. This type of assessment is particularly important in low-income settings, where the majority are left behind due to inadequate health financing and inaccessible healthcare services. The proposed assessment is timely given the ongoing health sector reforms in Tanzania, as described previously, which has the potential to influence equity in healthcare financing and benefits distribution. Our results from updated analyses will be compared with previous assessments, as a way to monitor progress towards the UHC objectives. We also produce baseline estimates for assessing the more recent reforms for future evaluation.

\section{Dissemination}

The findings will be disseminated through stakeholder meetings (eg, healthcare financing Technical Working Group at the Ministry of Health), peer-reviewed journal articles, policy briefs, local and international conferences and through social media platforms.

Twitter Peter Binyaruka @peter_binyaruka 
Contributors $\mathrm{PB}, \mathrm{AK}$, and MA conceptualised and designed the study protocol. PB wrote the first draft of the manuscript and finalised the manuscript.PB, AK, MA, MP and GM involved in data interpretation, presentation, and revision of manuscript. All authors (PB, AK, MA, MP, and GM) read and approved the final manuscript.

Funding The authors have not declared a specific grant for this research from any funding agency in the public, commercial or not-for-profit sectors.

Competing interests None declared.

Patient consent for publication Not required.

Provenance and peer review Not commissioned; externally peer reviewed.

Supplemental material This content has been supplied by the author(s). It has not been vetted by BMJ Publishing Group Limited (BMJ) and may not have been peer-reviewed. Any opinions or recommendations discussed are solely those of the author(s) and are not endorsed by BMJ. BMJ disclaims all liability and responsibility arising from any reliance placed on the content. Where the content includes any translated material, BMJ does not warrant the accuracy and reliability of the translations (including but not limited to local regulations, clinical guidelines, terminology, drug names and drug dosages), and is not responsible for any error and/or omissions arising from translation and adaptation or otherwise.

Open access This is an open access article distributed in accordance with the Creative Commons Attribution Non Commercial (CC BY-NC 4.0) license, which permits others to distribute, remix, adapt, build upon this work non-commercially, and license their derivative works on different terms, provided the original work is properly cited, appropriate credit is given, any changes made indicated, and the use is non-commercial. See: http://creativecommons.org/licenses/by-nc/4.0/.

\section{ORCID iD}

Peter Binyaruka http://orcid.org/0000-0002-1892-7985

\section{REFERENCES}

1 Stenberg K, Hanssen O, Edejer TT-T, et al. Financing transformative health systems towards achievement of the health sustainable development goals: a model for projected resource needs in 67 low-income and middle-income countries. Lancet Glob Health 2017;5:e875-87.

2 WHO. The world health report: health systems financing: the path to universal coverage. Geneva, Switzerland: World Health Organization, 2010.

3 Mills A, Ataguba JE, Akazili J, et al. Equity in financing and use of health care in Ghana, South Africa, and Tanzania: implications for paths to universal coverage. Lancet 2012;380:126-33.

4 Asante A, Price J, Hayen A, et al. Equity in health care financing in low- and middle-income countries: a systematic review of evidence from studies using benefit and financing incidence analyses. PLOS One 2016;11:e0152866.

5 Chan M. Making fair choices on the path to universal health coverage. Health Syst Reform 2016;2:5-7.

6 Meheus F, Mclntyre D. Fiscal space for domestic funding of health and other social services. Health Econ Policy Law 2017;12:159-77.

7 Lagomarsino G, Garabrant A, Adyas A, et al. Moving towards universal health coverage: health insurance reforms in nine developing countries in Africa and Asia. Lancet 2012;380:933-43.

8 Xu K, Evans DB, Carrin G, et al. Protecting households from catastrophic health spending. Health Aff 2007;26:972-83.

9 Mclntyre D, Thiede M, Dahlgren G, et al. What are the economic consequences for households of illness and of paying for health care in low- and middle-income country contexts? Soc Sci Med 2006;62:858-65

10 Kutzin J. Health financing for universal coverage and health system performance: concepts and implications for policy. Bull World Health Organ 2013;91:602-11.

11 Wagstaff A, van Doorslaer E, Calonge S, et al. Equity in the finance of health care: some international comparisons. J Health Econ 1992;11:361-87.

12 Wagstaff A, van Doorslaer E, van der Burg H, et al. Equity in the finance of health care: some further international comparisons. $J$ Health Econ 1999;18:263-90.

13 van Doorslaer E, Wagstaff A, van der Burg $\mathrm{H}$, et al. Equity in the delivery of health care in Europe and the US. J Health Econ 2000;19:553-83.

14 Borghi J, Ataguba J, Mtei G, et al. Methodological challenges in evaluating health care financing equity in data-poor contexts: lessons from Ghana, South Africa and Tanzania. Adv Health Econ Health Serv Res 2009;21:133-56.
15 Ataguba JE, Asante AD, Limwattananon S, et al. How to do (or not to do) ... a health financing incidence analysis. Health Policy Plan 2018;33:436-44.

16 Mclntyre D, Ataguba JE. How to do (or not to do) ... a benefit incidence analysis. Health Policy Plan 2011;26:174-82.

17 Wagstaff A, Van Doorslaer E, Paci P. Equity in the finance and delivery of health care: some tentative cross-country comparisons. Oxf Rev Econ Policy 1989;5:89-112.

18 O'Donnell O, Van Doorsslaer E, Wagstaff A. Analyzing health equity using household survey data: a guide to techniques and their implementation. World Bank Publications, 2008.

19 Akazili J, Mclntyre D, Kanmiki EW, et al. Assessing the catastrophic effects of out-of-pocket healthcare payments prior to the uptake of a nationwide health insurance scheme in Ghana. Glob Health Action 2017;10:1289735

20 Ataguba JE-O. Reassessing catastrophic health-care payments with a Nigerian case study. Health Econ Policy Law 2012;7:309-26.

21 Barasa EW, Maina T, Ravishankar N. Assessing the impoverishing effects, and factors associated with the incidence of catastrophic health care payments in Kenya. Int J Equity Health 2017;16:31.

22 Chuma J, Maina T. Catastrophic health care spending and impoverishment in Kenya. BMC Health Serv Res 2012;12:413.

23 Dorjdagva J, Batbaatar E, Svensson M, et al. Catastrophic health expenditure and impoverishment in Mongolia. Int $J$ Equity Health 2016;15:105.

24 Khan JAM, Ahmed S, Evans TG. Catastrophic healthcare expenditure and poverty related to out-of-pocket payments for healthcare in Bangladesh-an estimation of financial risk protection of universal health coverage. Health Policy Plan 2017;32:1102-10.

25 Koch KJ, Cid Pedraza C, Schmid A. Out-of-pocket expenditure and financial protection in the Chilean health care system-A systematic review. Health Policy 2017;121:481-94.

26 Kwesiga B, Zikusooka CM, Ataguba JE. Assessing catastrophic and impoverishing effects of health care payments in Uganda. BMC Health Serv Res 2015;15:30.

27 Masiye F, Kaonga O, Kirigia JM. Does user fee removal policy provide financial protection from catastrophic health care payments? Evidence from Zambia. PLoS One 2016;11:e0146508.

28 Mchenga M, Chirwa GC, Chiwaula LS. Impoverishing effects of catastrophic health expenditures in Malawi. Int $J$ Equity Health 2017;16:25.

29 Ngcamphalala C, Ataguba JE. An assessment of financial catastrophe and impoverishment from out-of-pocket health care payments in Swaziland. Glob Health Action 2018;11:1428473.

30 Mtei G. Health care financing progressivity and household risk protection in the context of health system financing reforms in Tanzania. University of London, 2012.

31 Mtei G, Makawia S, Ally M, et al. Who pays and who benefits from health care? An assessment of equity in health care financing and benefit distribution in Tanzania. Health Policy Plan 2012;27 Suppl 1:i23-34.

32 Mtei G, Makawia S, Masanja H. Monitoring and evaluating progress towards universal health coverage in Tanzania. PLoS Med 2014;11:e1001698.

33 NBS. Tanzania population and housing census: population distribution by administrative areas 2012. Dar es Salaam: National Bureau of Statistics (NBS), 2013.

34 WHO. National Health Accounts: Tanzania, 2014. Available: http://apps. who.int/nha/database/ViewData/Indicators/en [Accessed Jan 2021].

35 MOHCDGEC. National Health Accounts (NHA) for financial years 2013/14, 2014/15 and 2015/16. Tanzania: Ministry of Health Community Development, Gender, Elderly and Children (MoHCDGEC), 2019.

36 MoHSW. Mid term review of the health sector strategic plan III 2009-2015: health care financing. MoHSW, Dar es Salaam: Technical Report, Ministry of Health and Social Welfare (MoHSW), United Republic of Tanzania, 2013.

37 MoHCDGEC. Mid term review of the health sector strategic plan (HSSP) IV 2015-2020, main report. Tanzania: Ministry of Health Community Development, Gender, Elderly and Children (MoHCDGEC), 2019

38 Kruk ME, Mbaruku G, Rockers PC, et al. User fee exemptions are not enough: out-of-pocket payments for 'free' delivery services in rural Tanzania. Trop Med Int Health 2008;13:1442-51.

39 Manzi F, Schellenberg JA, Adam T, et al. Out-Of-Pocket payments for under-five health care in rural southern Tanzania. Health Policy Plan 2005;20 Suppl 1:i85-93.

40 MoHCDGEC. Improved CHF design document: short term plan towards universal health coverage. Tanzania: Ministry of Health Community Development, Gender, Elderly and Children (MoHCDGEC), 2018. 
41 Borghi J, Maluka S, Kuwawenaruwa A, et al. Promoting universal financial protection: a case study of new management of community health insurance in Tanzania. Health Res Policy Syst 2013;11:21.

42 MoHSW. Tanzania health sector strategic plan (HSSP IV) 2015-2020. Dar es Salaam: Ministry of Health and Social Welfare (MoHSW), 2015.

43 Maluka S, Chitama D. Primary health care systems (PRIMASYS): comprehensive case study from United Republic of Tanzania. World Health Organization (WHO), 2017.

44 Kapologwe NA, Kalolo A, Kibusi SM, et al. Understanding the implementation of direct health facility financing and its effect on health system performance in Tanzania: a non-controlled before and after mixed method study protocol. Health Res Policy Syst 2019;17:11.

45 MoHSW. Results based financing (RBF) design document. Dar es Salaam: Ministry of Health and Social Welfare (MOHSW), 2015.

46 MoFP. Ministry of Finance and Planning - Poverty Eradication Division (MoFP- PED) [Tanzania Mainland] and National Bureau of Statistics (NBS), 2019. Tanzania Mainland Household Budget Survey 2017-18, Key Indicators Report. Dodoma, Tanzania, 2019.

47 MoHSW. The cost of delivering health services in Tanzania: findings from a comprehensive costing analysis. Dar es Salaam: Ministry of Health and Social Welfare (MoHSW), 2013.
48 Vyas S, Kumaranayake L. Constructing socio-economic status indices: how to use principal components analysis. Health Policy Plan 2006;21:459-68.

49 Deaton A, Zaidi S. Guidelines for constructing consumption aggregates for welfare analysis. World Bank Publications, 2002.

50 Ataguba JE, McIntyre D. Paying for and receiving benefits from health services in South Africa: is the health system equitable? Health Policy Plan 2012;27 Suppl 1:i35-45.

51 Kakwani NC. Measurement of Tax progressivity: an international comparison. Econ J 1977;87:71-80.

52 Asante AD, Ir P, Jacobs B, et al. Who benefits from healthcare spending in Cambodia? Evidence for a universal health coverage policy. Health Policy Plan 2019;34:14-13.

53 Bowser D, Patenaude B, Bhawalkar M, et al. Benefit incidence analysis in public health facilities in India: utilization and benefits at the National and state levels. Int J Equity Health 2019;18:13.

54 Chuma J, Maina T, Ataguba J. Does the distribution of health care benefits in Kenya meet the principles of universal coverage? BMC Public Health 2012;12:20.

55 Kwesiga B, Ataguba JE, Abewe C, et al. Who pays for and who benefits from health care services in Uganda? BMC Health Serv Res 2015;15:44.

56 Wagstaff A, van Doorslaer E. Catastrophe and impoverishment in paying for health care: with applications to Vietnam 1993-1998. Health Econ 2003;12:921-33. 